\title{
Establishment of long-term high-fat diet and low dose streptozotocin-induced experimental type-2 diabetes mellitus model of insulin resistance and evaluation of seed extracts of Syzygium cumini
}

\author{
Pratibha Nadig $^{(\mathbb{D}}$, Meharban Asanaliyar ${ }^{\mathbb{D}}$, Kevin Manohar Salis ${ }^{(\mathbb{D}}$ \\ Department of Pharmacology, Vydehi Institute of Medical Sciences and Research Centre, Bangalore 560066, Karnataka, India
}

\section{A R T I C L E I N F O}

Article Type:

Original Article

\section{Article History:}

Received: 1 February 2021

Accepted: 26 March 2021

\section{Keywords:}

Diabetes mellitus

Diabetes model

High-fat diet

Streptozotocin

Insulin resistance

Syzygium cumini

\begin{abstract}
A B S T RAC T
Introduction: The principal mechanism responsible for reducing blood glucose is through insulin-stimulated glucose transport into skeletal muscle. The transporter protein that mediates this uptake is GLUT-4. A defect in this step is associated with reduced glucose utilization in muscle and adipose tissue, as observed in insulin-resistant type-2 diabetes mellitus (T2DM) patients. This study aimed to develop an experimental T2DM model and evaluate altered glucose transporter type 4 (GLUT-4) levels as a biomarker of insulin resistance. Antidiabetic activities of Syzygium cumini hydro-ethanolic seed extracts (SCE) were also evaluated.

Methods: Adult male Wistar albino rats were fed a high-fat diet for 12 weeks and dosed intraperitoneally with streptozotocin $(35 \mathrm{mg} / \mathrm{kg})$. After treatment for 21 days, all investigations were done. The homeostasis model of assessment (HOMA) was used for the calculation of insulin resistance (HOMA-IR) and beta-cell function (HOMA-B) index. Diaphragm muscle and retroperitoneal fat were collected for real-time polymerase chain reaction (RT-PCR) studies.

Results: A significant increase in fasting blood glucose, HOMA-IR, and serum lipids, and a decrease in serum insulin and HOMA-B were observed in the diabetic group, effects that reversed following pioglitazone and SCE treatment. The diabetic group showed a downregulation of GLUT-4 expression in skeletal muscle while an increase was observed in adipose tissue.

Conclusion: A high-fat diet and low dose streptozotocin-induced experimental T2DM model of insulin resistance was developed to screen novel insulin sensitizers. Data generated demonstrated that altered GLUT-4 levels could be used as a biomarker of insulin resistance. Antidiabetic activity of $S$. cumini hydro-ethanolic seed extract was also confirmed in this study.
\end{abstract}

Implication for health policy/practice/research/medical education:

The research is relevant to public health as it involves identification of genetic biomarker related to the understanding of insulin resistance and developing a screening model for identification of insulin sensitizers.

Please cite this paper as: Nadig P, Asanaliyar M, Salis KM. Long-term high-fat diet and low dose streptozotocin-induced experimental type-2 diabetes mellitus model of insulin resistance and evaluation of seed extracts of Syzygium cumini. J Herbmed Pharmacol. 2021;10(3):331-338. doi: 10.34172/jhp.2021.38.

\section{Introduction}

Type-2 diabetes mellitus (T2DM) patients suffer from a dual-pronged effect of both impaired insulin secretion from pancreatic beta cells and insulin resistance (IR). IR is defined as an impaired ability of the peripheral tissues to respond to insulin resulting in hyperglycemia that eventually leads to diminished insulin secretion (1). Other than effects on blood glucose levels, IR is also linked to increased (2-3 fold) risks of microvascular complications (2).

Tissue unresponsiveness to insulin is due to diminished insulin mediated signaling and other multiple intracellular 
defects of post-receptor interaction. Glucose transport into skeletal muscle through GLUT-4 is considered an important step for whole-body glucose uptake. This has a primary role in IR in T2DM (3). GLUT-4 translocates itself to the cell membrane and mediates insulin stimulated glucose transport by activating the phosphatidylinositol 3-kinase (PI3K)/phosphorylated protein kinase B (P-AKT) pathway (4).

Defects in GLUT-4 translocation have been shown to be linked to reduced glucose utilization in muscle and adipose tissues of insulin-resistant T2DM patients (5). Such deficiencies could be due to genetic and/or acquired factors. Moreover, there is a strong association between IR and expression of solute carrier family 2 member 4 (SLC2A4) genes that code for GLUT-4 in skeletal muscle membranes (3). GLUT-4 knockout mice have shown development of IR and diabetes (6).

In a study, high fat diet for 2 weeks followed by a single intraperitoneal dose of streptozotocin (35 mg/kg) in rats increased IR by 10 times (7). Also, pioglitazone and extracts of Tinospora cordifolia could reverse the effects of a combination of high fat and high sugar diet along with streptozotocin (8). An enhanced expression of PPAR gamma in the liver, skeletal muscle, and adipose tissue, and a consequent reduction of GLUT-4 translocation and expression in diabetic models following a 2-week high fat diet in conjunction with low dose streptozotocin treatment were also reported. These effects could be reversed with gallic acid (9).

The models described above have been successful in inducing IR but have used either a shorter duration of highfat diet, like 10 days, or up to a longer period of four weeks. Further, they simulated certain metabolic abnormalities in individuals at risk for developing T2DM because of IR or early diabetes and not proven T2DM. Hence, we wanted to develop a model for established T2DM where there would be IR along with reduced pancreatic beta cell function. Since the pathogenesis of T2DM in humans involves the development of diabetes due to altered lifestyle, including changes in dietary habits like regular intake of high fat foods, we felt that it is worth evaluating the influence of long term high-fat diet in rat model (11). Moreover, there is limited literature available with regards to the expression of GLUT-4 genes in such experimental diabetic models. Hence, we aimed to develop an animal model with an altered GLUT-4 expression similar to that observed in humans. The specific objectives were to observe the effect of a long term (12 weeks) high fat diet followed by administration of a low dose streptozotocin on Fasting blood glucose (FBG), serum insulin, serum lipids, and the concomitant monitoring of GLUT-4 expression in rat skeletal muscle and adipose tissues. HOMA-IR and HOMA-B, which indicate IR and beta cell function respectively were also included as phenotypic evidence.

Pioglitazone, a thiazolidinedione based insulin sensitizer was chosen as the standard drug for validating this strategy. It improves the expression of PPAR gamma in the liver and skeletal muscle thereby leading to increased GLUT-4 translocation into these tissues (9).

Syzygium cumini called Eugenia jambolana is a medicinal plant with antidiabetic properties. The aqueous and ethyl acetate fractions of hydro-methanolic seed extracts of this plant have shown significant anti-diabetic activity in streptozotocin-induced diabetes when dosed for 21 days and 35 days, respectively in Wistar albino rats at a dose of $200 \mathrm{mg} / \mathrm{kg}(10,12)$. During our preliminary anti-diabetic studies with the hydro-ethanolic seed extract of S. cumini at doses of 100, 200 and $400 \mathrm{mg} / \mathrm{kg}$ in Wistar albino rats, we observed a significant reduction in the FBG in rats fed with high-fat diet and streptozotocin-induced T2DM (dosed with $200 \mathrm{mg} / \mathrm{kg}$ ) (unpublished data). Hence the same was taken as another control.

\section{Materials and Methods}

This study was conducted following approval by the Institutional Animal Ethics Committee (VIMS/1AEC/2016/02), which is registered under CPCSEA. All experimental protocols were carried out based on the ethical principles stipulated by the CPCSEA.

The standardized hydro-ethanolic seed extract of $S$. cumini was procured from Natural remedies Pvt Ltd, Bangalore. (Batch number; FSCEX/2015090001). This extract was standardized to contain polyphenols $(29.4 \%$ by spectrophotometry) and ellagic acid ( $2.8 \%$ by high performance liquid chromatography, HPLC). The certificate of analysis indicates that the heavy metal content, microbial counts, aflatoxin, and residual solvents were as per the standards laid down by British Pharmacopeia (BP) and United States Pharmacopeia Standards (USP) (data on file). The procedure followed by the manufacturer was as follows: briefly, the powdered raw material was first extracted with $50 \%$ ethanol under reflux at $70^{\circ} \mathrm{C}$ and the solvent filtered. The remaining raw material was once again kept for reflux with fresh 50\% ethanol for one hour, the process again repeated twice and then filtered. The liquid filtrates were combined, concentrated using RotaVapour under vacuum to get a thick paste at a temperature not more than $60^{\circ} \mathrm{C}$ of the hydro ethanolic extract. These extractions resulted in a final yield of $\sim 20 \%$.

\section{Experimental animals}

Healthy adult male inbred Wistar albino rats aged 3-4 months weighing 180-200 g were housed in polypropylene cages with clean paddy husk bedding, maintained under controlled temperature of $25^{\circ} \mathrm{C} \pm 2{ }^{\circ} \mathrm{C}$. A 12-hour light/ dark cycle was maintained with food and water provided ad libitum.

\section{Induction of diabetes}

A high-fat diet comprising vanaspati ghee and coconut oil in the ratio of $3: 1(\mathrm{v} / \mathrm{v})$ was introduced $(3 \mathrm{~mL} / \mathrm{kg})$ via an intra-gastric tube (8) once a day for 12 weeks in addition 
to the standard chow provided in the form of pellets. The composition of high-fat diet is given in Table 1 . After 12 weeks, a single intraperitoneal injection of freshly prepared streptozotocin $(35 \mathrm{mg} / \mathrm{kg}$ in $0.1 \mathrm{M}$ citrate-phosphate buffer, pH 4.5; Sigma Aldrich) was given. In order to prevent sudden hypoglycemia, immediately following streptozotocin injection on the first day, the animals were given $10 \%$ glucose and $1 \%$ normal saline orally. For the next two consecutive days, $5 \%$ glucose and $1 \%$ saline were given. The animals were then stabilized for 1 week after which they were evaluated for FBG and fasting serum insulin using Contour TS Clinical Glucometer and rat insulin ELISA kit (KINESISDx, LA, USA, Catalog number: K11-0708, Lot number: RI0118), respectively. The serum triglycerides and serum cholesterol were estimated using the procedures outlined in commercial kits (Agappe Diagnostics Ltd. Ernakulam, India). Blood samples for biochemical investigations were collected through retroorbital puncture.

Estimation of IR and pancreatic $\beta$-cell function IR and $\beta$-cell functions were mathematically calculated by the homeostasis model assessment method (HOMA). The following equations were used for the calculations (13):

HOMA-IR $($ for Insulin resistance $)=($ glucose in $\mathrm{mmol} / \mathrm{L}) / 22.5$

HOMA-B (for beta cell function $)=(20 X$ Fasting insulin $\mathrm{mI}$ $U / L) /($ Fasting glucose in $\mathrm{mmol} / \mathrm{L}-3.5)$

The animals with FBG above $200 \mathrm{mg} / \mathrm{dL}$ were selected and randomly allocated to experimental groups.

\section{Experimental design}

Six animals were given a normal diet, and 25 animals received a high-fat diet for 12 weeks, followed by streptozotocin. Twenty-two animals showed FBG above $200 \mathrm{mg} / \mathrm{dL}$, which were divided into the diabetic group, pioglitazone group, and SCE group. Since the diabetic group without treatment was likely to show some mortality based on prior pilot studies, more animals were allocated to this group.

Groups:

- Normal: normal animals that received the vehicle ( $1 \%$ carboxymethylcellulose) (CMC) in water.

- Diabetic: diabetic animals that received only CMC

- Pioglitazone: diabetic animals treated with pioglitazone $(10 \mathrm{mg} / \mathrm{kg}$ in $\mathrm{CMC})$

- $\quad$ SCE: diabetic animals treated with SCE $(200 \mathrm{mg} / \mathrm{kg}$ in $\mathrm{CMC}$ )

Treatments were given orally once a day for 21 days. The animals were observed daily, and their food intake, body weight, and general health conditions were monitored. All the investigations mentioned above were repeated after 21 days of treatment. Thereafter, animals were sacrificed by
Table 1. Composition of the high-fat diet provided to Wistar albino rats

\begin{tabular}{lll}
\hline Components & Indian vanaspati & Coconut oil \\
\hline Ratio & Three parts & One part \\
Percentage of TFA & $>20 \%$ & $9 \%$ \\
Percentage SFA & $>60 \%$ & $\sim 90 \%$ \\
\hline
\end{tabular}

Abbreviations: TFA, trans-fatty acid; SFA, saturated fatty acid.

anesthesia with an overdose of ether, and their diaphragm and retroperitoneal fat collected for further analysis.

Expression of GLUT-4 gene using real-time polymerase chain reaction/quantitative polymerase chain reaction (RT-PCR/qPCR)

The dissection of animals was carried out in the department of pharmacology at our institute. Three animals from each group were sacrificed. The diaphragms and retroperitoneal fat were collected. Tissues were snapfrozen in liquid nitrogen and stored in the deep freezer at $-80^{\circ} \mathrm{C}$ until further analysis.

RNA was extracted from the retroperitoneal fat and diaphragm muscle by the standard Trizol (Ambion Cat\#15596018) RNA extraction method as per the manufacturer's instructions using Qiagen RNeasy mini kit column. The isolated total RNA was quantified by measuring absorbance at $260 \mathrm{~nm}$ (NanoDrop, ND2000), and the purity assessed using 260/230 and 260/280 ratios for salts and protein contamination, respectively. The integrity of total RNA was assessed in bio-analyzer (Agilent 2000, Agilent Technologies USA) using RNA 6000 Nano Lab Chip (Agilent Technologies, USA). RNA integrity (RIN) was calculated by considering $18 \mathrm{~S}$ and $28 \mathrm{~S}$ ribosomal RNA ratios and baseline correction factors. The samples with $>6$ RIN were considered for relative quantification.

The primers were designed for selected genes using Primer 3 Plus online primer design software considering the exonic and coding region of the transcripts. The designed primers were analyzed for their specificity by In-Silico PCR in NCBI-BLAST online bio-informatics tool, and the primer characteristics were analyzed in multiple primer analyzers (Thermo Scientific, USA) for the possibility of primer dimer formation. The primer sequence, which qualified all the quality criteria, were processed for synthesis on a $10 \mathrm{~nm}$ scale and purified by HPLC. The genes coding for $\beta$-actin and GLUT- 4 were selected as housekeeping and test gene for the study. The following primers were used

1. ACTIN_FP AAGGCCAACCGTGAAAAGATGA.

2. ACTIN_RP CCAGAGGCATACAGGGACAACA

3. GLUT-4_FP TTGTGGCCGAGCTCTTCAGC;

4. GLUT-4_RP GGGACCCATAGCATCCGCAA.

Real-time PCR (RT-PCR/qPCR)

The expression levels of selected genes were analyzed 
using SYBR Green chemistry (Brilliant II SYBR Green qPCR master mix, Agilent Technologies, USA) in a Strata gene mx3005P instrument (Agilent Technologies, USA). The amplification cycling conditions were as follows: Initial denaturation for $95^{\circ} \mathrm{C}$ for 10 minutes followed by 40 cycles of $95^{\circ} \mathrm{C}$ for 30 seconds, $60^{\circ} \mathrm{C}$ for 30 seconds. The mean $\mathrm{Ct}$ value of technical replicates was used to calculate the relative expression level of genes. The relative quantification of genes was analyzed using standard $2^{\wedge}$ $\Delta \Delta \mathrm{Ct}$ as described by Pfaffl (14). GAPDH was used as reference gene to normalize the qPCR experiment.

\section{Statistical analysis}

One way ANOVA was applied to observe the statistical significance. $\quad P<0.05$ was considered statistically significant. All the statistical analysis was performed using SPSS version 21.

\section{Results}

Effect oflong-term high fat diet and low dose streptozotocin on body weight, feed intake and general behaviour

There were no significant differences between the animal groups with regards to body weight, as shown in Table 2. Moreover, there was also no significant difference in feed intake and general behaviour. Twenty-five animals were given a high-fat-diet and six animals were given a normal diet for 12 weeks. No mortality was observed during these 12 weeks in any of these. After injecting streptozotocin to the high-fat-fed animals, 22 showed fasting blood glucose above $200 \mathrm{mg} / \mathrm{dL}$ and hence grouped together for the

Table 2. Effect of long-term high fat diet and low dose streptozotocin on rat body weight

\begin{tabular}{lcc}
\hline Group & $\begin{array}{c}\text { Body weight in grams } \\
\text { Day 0 }\end{array}$ & $\begin{array}{c}\text { Bodyweight in grams } \\
\text { Day 21 }\end{array}$ \\
\hline Normal & $298.33 \pm 31.88$ & $326.67 \pm 40.82$ \\
Diabetic & $306.67 \pm 23.38$ & $330 \pm 15.49 *$ \\
Pioglitazone & $303.33 \pm 52.78$ & $330 \pm-53.29 *$ \\
SCE & $305 \pm 41.35$ & $331.67 \pm 35.44^{*}$ \\
\hline
\end{tabular}

The data are expressed as mean \pm SD, $n=6$ per group. SCE, Syzygium cumini hydro-ethanolic seed extract; $* P>0.05$ compared to the normal group. study. Thus these 22 diabetic animals were distributed as follows: 8 in the diabetic group, 7 in each of the treated groups. Two animals in the diabetic group and one in each of the treated groups, died in the initial two weeks after induction on different days. The data reported here is of 6 animals per group as they survived 21 days of treatment. The animals in the untreated diabetic group appeared to be less active as compared to the other group of animals.

Effect of long-term high fat diet and low dose streptozotocin on diabetic induction, fasting blood glucose, and serum insulin levels

A significant increase in the fasting blood glucose levels and a decrease in serum insulin levels in the diabetic group as compared to the normal rats on day 21 was observed. On the other hand, both pioglitazone and the SCE treatment groups showed a significant reduction in fasting blood glucose along with an increase in plasma insulin levels (Table 3).

Effect of the high-fat-diet and low-dose streptozotocin on HOMA IR and HOMA B

As shown in Table 4, there was a significant increase in the HOMA-IR levels and a decrease in the HOMA- B levels in the diabetic group as compared to the normal group that did not change after 3 weeks. HOMA-IR was significantly reversed on treatment with SCE but not with pioglitazone. HOMA-B was increased in the pioglitazone and SCE groups.

Effect of long-term high-fat diet and low dose streptozotocin on serum triglycerides and cholesterol The diabetic group showed elevated levels of both serum triglycerides and cholesterol. Treatment with pioglitazone and SCE showed a statistically significant reduction in these metabolites when compared to the diabetic group (Table 5).

Effect of long-term high-fat diet and low dose streptozotocin on GLUT-4 expression in rat diaphragm (fold change)

As seen in Figure 1, in comparison with the normal group, there was a down-regulation of GLUT-4 in the diabetic

Table 3. Effect of long-term high fat diet and low dose streptozotocin on fasting blood glucose and serum insulin levels

\begin{tabular}{lcccc}
\hline Groups & $\begin{array}{c}\text { FBG }(\mathrm{mg} / \mathrm{dL}) \\
\text { Day 0 }\end{array}$ & $\begin{array}{c}\text { FBG }(\mathrm{mg} / \mathrm{dL}) \\
\text { Day 21 }\end{array}$ & $\begin{array}{c}\text { Fasting serum insulin }(\mathrm{mIU} / \mathrm{L}) \\
\text { Day 0 }\end{array}$ & $\begin{array}{c}\text { Fasting serum insulin }(\mathrm{mIU} / \mathrm{L}) \\
\text { Day 21 }\end{array}$ \\
\hline Normal & $73.5 \pm 12.5$ & $78.33 \pm 6.53$ & $14.35 \pm 3.05$ & $16.28 \pm 4.49$ \\
Diabetic & $419.50 \pm 131.38$ & $414.83 \pm 129.16^{*}$ & $6.47 \pm 4.14$ & $7.13 \pm 3.74 *$ \\
Pioglitazone, $10 \mathrm{mg} / \mathrm{kg}$ & $293.00 \pm 143.46$ & $121.50 \pm 53.10^{* *}$ & $6.80 \pm 2.55$ & $15.70 \pm 5.40 * *$ \\
SCE $200 \mathrm{mg} / \mathrm{kg}$ & $306.17 \pm 108.69$ & $96.00 \pm 8.32 * *$ & $7.99 \pm 5.15$ & $12.00 \pm 1.57 * *$ \\
\hline
\end{tabular}

Abbreviation: FBG, Fasting blood glucose.

Values are expressed as mean \pm standard deviation $(n=6) . * P<0.05$ compared to the normal control $* * P<0.05$ compared to the diabetic control. SCESyzygium cumini seed hydro-ethanolic extract 
Table 4. Effect of long-term high fat diet and low dose streptozotocin on HOMA-IR and HOMA-B

\begin{tabular}{lccc}
\hline Groups & $\begin{array}{c}\text { HOMA-IR } \\
\text { Day 0 }\end{array}$ & $\begin{array}{c}\text { HOMA-IR } \\
\text { Day 21 }\end{array}$ & $\begin{array}{c}\text { HOMA- B } \\
\text { Day 0 }\end{array}$ \\
\hline Normal & $2.61 \pm 0.70$ & $3.14 \pm 0.81$ & $68.15 \pm 18.93$ \\
Diabetic & $6.15 \pm 3.46$ & $6.95 \pm 3.81^{*}$ & $6.62 \pm 3.17$ \\
Pioglitazone, $10 \mathrm{mg} / \mathrm{kg}$ & $4.41 \pm 1.07$ & $4.72 \pm 2.80^{* *}$ & $6.89 \pm 6.23$ \\
SCE $200 \mathrm{mg} / \mathrm{kg}$ & $5.85 \pm 3.70$ & $2.85 \pm 0.46 * *$ & $6.61 \pm 3.82^{*}$ \\
\hline
\end{tabular}

SCE, Syzygium cumini seed hydro-ethanolic extract; HOMA-IR, Homeostasis model of assessment of insulin resistance; HOMA-B: Homeostasis model of assessment for pancreatic beta cell function.

Values are expressed as mean \pm standard deviation $(n=6) .{ }^{*} p<0.05$ compared to the normal control. ${ }^{* *} p<0.05$ compared to the diabetic control.

Table 5. Effect of long-term high fat diet and low dose streptozotocin on serum triglycerides and cholesterol

\begin{tabular}{|c|c|c|c|c|}
\hline $\begin{array}{l}\text { Group } \\
\text { ( } n=6 \text { in each group) }\end{array}$ & $\begin{array}{c}\text { Serum triglycerides } \\
(\mathrm{mg} / \mathrm{dL}) \\
\text { Day } 0\end{array}$ & $\begin{array}{c}\text { Serum triglycerides } \\
\text { (mg/dL) } \\
\text { Day } 21\end{array}$ & $\begin{array}{c}\text { Serum cholesterol } \\
\text { (mg/dL) } \\
\text { Day } 0\end{array}$ & $\begin{array}{c}\text { Serum cholesterol } \\
(\mathrm{mg} / \mathrm{dL}) \\
\text { Day } 21\end{array}$ \\
\hline Normal & $89.0 \pm 2.677$ & $89.41 \pm 2.30$ & $118.77 \pm 5.77$ & $117.09 \pm 17.56$ \\
\hline Diabetic & $144.25 \pm 4.45$ & $145.19 \pm 1.17^{*}$ & $173.68 \pm 3.47$ & $170.09 \pm 1.97 *$ \\
\hline Pioglitazone, $10 \mathrm{mg} / \mathrm{kg}$ & $138.88 \pm 13.75$ & $95.59 \pm 0.622 * *$ & $163.04 \pm 1.44$ & $130.40 \pm 1.92 * *$ \\
\hline SCE $200 \mathrm{mg} / \mathrm{kg}$ & $142.95 \pm 2.09$ & $122.65 \pm 1.72 * *$ & $161.80 \pm 10.46$ & $141.90 \pm 1.92 * *$ \\
\hline
\end{tabular}

SCE, Syzygium cumini seed hydro-ethanolic extract

Values are expressed as mean \pm standard deviation $(n=6) . * P<0.05$ compared to the normal control. ${ }^{* *} P<0.05$ compared to the diabetic control.

group by 0.67 -fold (expressed as -0.67). Pioglitazone and SCE reversed this down-regulation towards normal though it was not so pronounced in the SCE group.

Effect oflong-term high fat diet and low dose streptozotocin on GLUT-4 expression in rat adipose tissue (fold change) RT- PCR was done similarly for the GLUT-4 gene expression in diabetic rat adipose tissue after treating them for three weeks. In contrast to that observed in diaphragm tissue, as shown in Figure 2, there was an up-regulation of GLUT-4 in the rat adipose tissue (2.32-fold) as compared to the normal group. Pioglitazone and SCE treated animals showed a fold change value of 1.82 and 1.64 respectively,

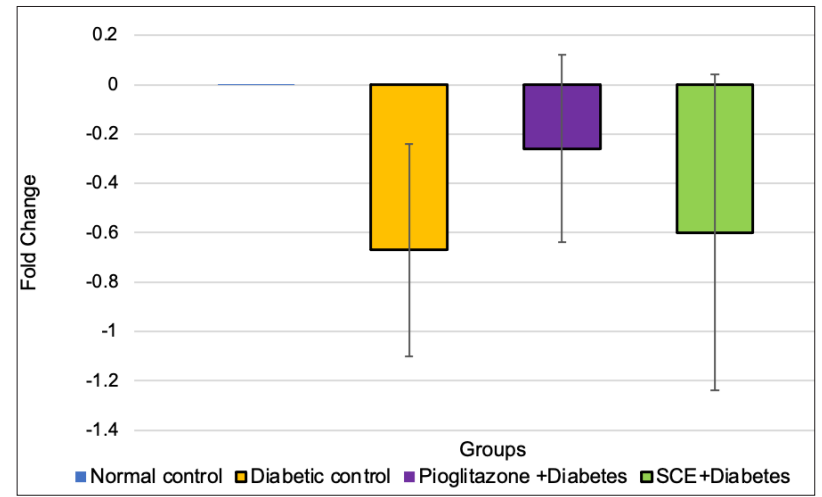

Figure 1. Effect of long-term high-fat diet and low-dose streptozotocin on glucose transporter -4 (GLUT-4) gene expression in rat skeletal muscle. The results are expressed as the relative fold change to the log base -2 in all the groups with reference to the normal group. The values are expressed as mean of 3 animals +/-SEM, each testing done in triplicate. SCE-Syzygium cumini seed hydro-ethanolic extract. indicating a reduction in the up-regulation.

The results are expressed as relative fold change to the $\log$ base -2 in all the groups with reference to the normal group. The values are expressed as mean of three animals +/-SEM, each testing done in triplicate. SCE-Syzygium cumini seed hydro-ethanolic extract.

\section{Discussion}

The present study was intended to determine whether long-term feeding of high fat followed by streptozotocin administration would alter the GLUT-4 expression in the skeletal muscle and adipose tissues. Further, this change could then serve as a genetic biomarker to track the

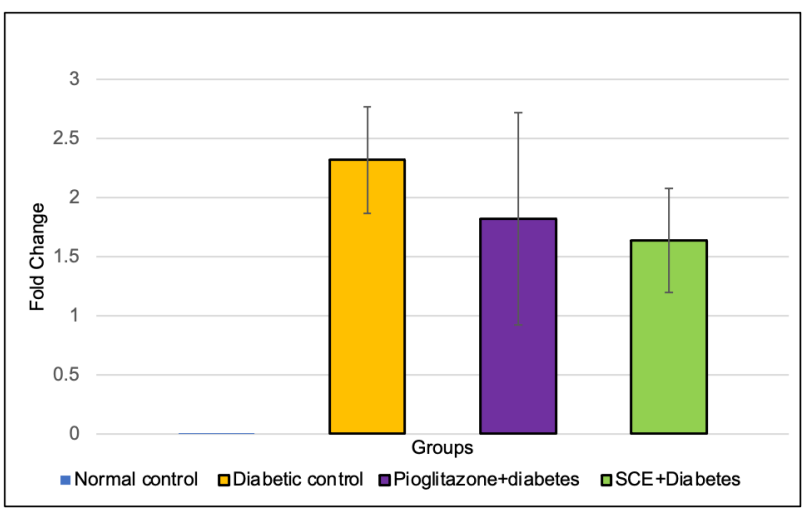

Figure 1. Effect of long-term high-fat diet and low-dose streptozotocin on glucose transporter -4 (GLUT-4) gene expression in rat skeletal muscle. The results are expressed as the relative fold change to the log base -2 in all the groups with reference to the normal group. The values are expressed as mean of 3 animals +/-SEM, each testing done in triplicate. SCE-Syzygium cumini seed hydro-ethanolic extract. 
development of IR at a molecular level in the rat model.

We observed a significant increase in fasting blood glucose, a decrease in beta-cell dysfunction, an increase in IR, an elevation in plasma lipids and a decreased GLUT-4 expression in diaphragm muscle of the diabetic rats as compared to the normal rats. These effects were reversed with pioglitazone and SCE treatment. Hence, we considered this model as a reliable and validated model to simulate induction of type-2 like diabetes in Wistar albino rats.

We observed only a 7 to $8 \%$ increase in body weight for diabetic rats from day 0 to 21 . It can be due to streptozotocin, as it is known to reduce weight gain in similar models (15).

Insulin improves glucose tolerance by activation of PIP3-AKT pathway resulting in the translocation of intracellularly located GLUT-4 receptors to the membrane. GLUT-4 receptors facilitate the diffusion of glucose across the membrane in the cells of peripheral tissues such as the skeletal muscle and the adipose tissue (16). In this model, streptozotocin probably reduced the beta cell function by inducing the oxidative damage of islets of Langerhans and consequently the insulin levels (17). Further, highfat feeding selectively impairs insulin-stimulated glucose transport by reducing GLUT- 4 translocation to the plasma membrane. This phenomenon is due to an acquired defect in insulin activation of PI 3-kinase, the first step in the insulin signaling pathway (18).

The increase in HOMA-IR and the down-regulation of GLUT-4 in the diaphragm (skeletal muscle) of the diabetic group could be due to the above-mentioned mechanisms. Pioglitazone group showed a significant reduction in the FBG but did not improve HOMA-IR, significantly although there was an up-regulation of the GLUT-4 expression in the skeletal muscle. However, similar studies with pioglitazone in high fat-induced IR have shown to improve both peripheral and brain insulin sensitivity $(9,9)$. It appears that either the dose or the duration of treatment of pioglitazone could have been insufficient to reduce the overall IR in this model. SCE did not show a significant upregulation of GLUT-4 in skeletal muscle, although it has shown improved HOMA-IR significantly.

SCE reduced the HOMA-IR in this study, similar to the report by Sharma et al, wherein a decrease in IR and fasting blood sugar with an aqueous seed extract of this plant was shown. They attributed these effects to the alterations in the hepatic PPAR alpha and gamma (10). As per the manufacturer's certificate of analysis, SCE contains more than $20 \%$ of polyphenols and more than $2 \%$ of ellagic acid (data on file). Studies on pure commercial ellagic acid have shown to improve insulin sensitivity in skeletal muscle by upregulating GLUT-4 and PPAR gamma in in vitro studies (20). This seems to be the probable mechanism of action SCE.

The reduced HOMA-B (pancreatic beta-cell function) in the diabetic rats in this model can be explained to be due to the prolonged simulation of the pancreas in the initial stages of hyperglycemia as well as due to the action of streptozotocin. Our study demonstrated an improvement in HOMA-B with pioglitazone. Recent studies with pioglitazone have shown that in addition to an improvement in IR, this drug also improves betacell function in T2DM patients (21). Pioglitazone has also been shown to regenerate the beta cells in diabetic mice (22).

Hence, our study is a confirmation of this finding as not much literature in this regard is available on pioglitazone. SCE has also shown a significant improvement in beta-cell function, albeit not as much as that of pioglitazone. This may be attributed to the presence of polyphenols in SCE. Polyphenols like quercetin have been shown to be potent antioxidants protecting the beta cells from oxidative damage caused by streptozotocin (23).

One of the striking observations in our study was an upregulation of GLUT- 4 in the rat adipose tissue as observed by the fold change. The same was not so with pioglitazone and SCE. This is in contrast to other studies which demonstrated a down-regulation of GLUT-4 expression in adipose tissue in diabetic animals $(9,24,25)$.

This difference might be due to a longer duration of high-fat feeding (12 weeks vs. 2-4 weeks) or a difference in the strain, age, and sex of the animals used in our study as compared to the previous reports. Some studies on transgenic mice have established that in the event of an increase in whole-body IR, moderate over-expression of GLUT-4 is seen in adipose tissue as a compensatory mechanism to improve insulin sensitivity $(26,27)$. Our observations could also be due to similar reasons. This effect was not so pronounced in the pioglitazone and SCE groups in this aspect as these two drugs reduced the whole-body IR as seen by decreased HOMA-IR. This further validates the hypothesis that up-regulation could have been a compensatory mechanism.

In comparison with the previous studies that used a shorter duration of high-fat diet (2-4 weeks) followed by low dose streptozotocin $(9,10)$, our study showed a similar increase in IR. However, the magnitude of IR in the diabetic group was three times (9) and six times (10) than normal control, while our study showed twice than normal group animals. In addition, these short-duration models were characterized by hyperglycemia and hyper-insulinemia, which typically mimics early T2DM in humans in contrast to our study where there was hyperglycemia and reduced insulin levels similar to late T2DM (28). As far as genetic markers were concerned, Gandhi et al (9) demonstrated a down-regulation of PPAR gamma expression in the adipose tissue of the skeletal muscle, which was similar to that reported in our study. There was also a downregulation of GLUT -4 in the adipose tissue, an effect in contrast to our observations, the likely reasons for which are explained above. 


\section{Conclusion}

High-fat diet in the form of vanaspati ghee and coconut oil in the ratio of $3: 1(\mathrm{v} / \mathrm{v})$, in addition to standard chow for 12 weeks followed by a dose of $35 \mathrm{mg} / \mathrm{kg}$ streptozotocin seems to be a suitable T2DM model to screen novel insulin sensitizers that brings about altered GLUT-4 expression in the skeletal muscle and adipose tissues. This study established that long-term high-fat feeding down-regulated GLUT-4 in the skeletal muscle but may up-regulate the same in adipose tissue. There are limited reports in this area, and it is worth exploring further. Extending the studies towards understanding the intracellular signaling pathways, particularly the PIP-3, AKT, and other pathways using microarrays could establish the underlying pathology in T2DM in younger patients, especially on the influence of various epigenetic factors such as diet and sedentary lifestyle. In this study, the antidiabetic activity of $S$. cumini hydro-ethanolic seed extract was also confirmed.

\section{Limitations of the study}

The study provided data on six animals per group. As there were variations in the responses to high-fat feeding followed by streptozotocin and mortality, a larger number of at least 8-10 would have minimized the standard deviations and standard errors of mean. RT-PCR could also have been carried out with tissues from all the six animals but owing to limited resources, not all were tested.

\section{Acknowledgement}

The authors are thankful to the management, the principal for providing the necessary infrastructure and all the faculty members of the department of pharmacology for the support in conducting the experiments.

\section{Authors' contributions}

PD conceived the idea, research hypothesis and the protocol for the experiments, contributed to the development, and drafted the manuscript. MA conducted the work, analyzed the results, and contributed to manuscript writing. KMS contributed to conducting animal experiments.

\section{Conflict of interests}

The authors declare no conflict of interest.

\section{Ethical considerations}

The study was approved by Institutional Animal Ethics committee (IAEC) of Vydehi Institute of Medical science and Research Centre (VIMS\&RC), Bangalore, India (VIMS/IAEC/2016/01). Ethical issues of plagiarism, misconduct, data fabrication, falsification, double publication or redundancy have been completely observed by the authors

\section{Funding/Support}

The study was conducted under the research grant received from Rajiv Gandhi University of Health Sciences, Bangalore (Order 059/2016-17 grant no. M087).

\section{References}

1. Diagnosis and classification of diabetes mellitus. Diabetes Care. 2011;34 Suppl 1:S62-9. doi: 10.2337/dc11-S062.

2. Ormazabal V, Nair S, Elfeky O, Aguayo C, Salomon C, Zuñiga FA. Association between insulin resistance and the development of cardiovascular disease. Cardiovasc Diabetol. 2018;17(1):122. doi: 10.1186/s12933-018-0762-4.

3. Bouzakri K, Koistinen HA, Zierath JR. Molecular mechanisms of skeletal muscle insulin resistance in type 2 diabetes. Curr Diabetes Rev. 2005;1(2):167-74. doi: 10.2174/1573399054022785.

4. Klip A, Sun Y, Chiu TT, Foley KP. Signal transduction meets vesicle traffic: the software and hardware of GLUT4 translocation. Am J Physiol Cell Physiol. 2014;306(10):C879-86. doi: 10.1152/ajpcell.00069.2014.

5. Corrêa-Giannella ML, Machado UF. SLC2A4gene: a promising target for pharmacogenomics of insulin resistance. Pharmacogenomics. 2013;14(8):847-50. doi: 10.2217/pgs.13.45.

6. Stenbit AE, Tsao TS, Li J, Burcelin R, Geenen DL, Factor SM, et al. GLUT4 heterozygous knockout mice develop muscle insulin resistance and diabetes. Nat Med. 1997;3(10):1096101. doi: 10.1038/nm1097-1096.

7. Srinivasan K, Viswanad B, Asrat L, Kaul CL, Ramarao P. Combination of high-fat diet-fed and low-dose streptozotocin-treated rat: a model for type 2 diabetes and pharmacological screening. Pharmacol Res. 2005;52(4):31320. doi: 10.1016/j.phrs.2005.05.004.

8. Munshi RP, Joshi SG, Rane BN. Development of an experimental diet model in rats to study hyperlipidemia and insulin resistance, markers for coronary heart disease. Indian J Pharmacol. 2014;46(3):270-6. doi: 10.4103/02537613.132156.

9. Gandhi GR, Jothi G, Antony PJ, Balakrishna K, Paulraj $\mathrm{MG}$, Ignacimuthu $\mathrm{S}$, et al. Gallic acid attenuates highfat diet fed-streptozotocin-induced insulin resistance via partial agonism of PPAR $\gamma$ in experimental type 2 diabetic rats and enhances glucose uptake through translocation and activation of GLUT4 in PI3K/p-Akt signaling pathway. Eur J Pharmacol. 2014;745:201-16. doi: 10.1016/j. ejphar.2014.10.044.

10. Sharma AK, Bharti S, Kumar R, Krishnamurthy B, Bhatia J, Kumari S, et al. Syzygium cumini ameliorates insulin resistance and $\beta$-cell dysfunction via modulation of PPAR, dyslipidemia, oxidative stress, and TNF- $\alpha$ in type 2 diabetic rats. J Pharmacol Sci. 2012;119(3):205-13. doi: 10.1254/ jphs.11184fp.

11. McAuley K, Mann J. Thematic review series: patientoriented research. Nutritional determinants of insulin resistance. J Lipid Res. 2006;47(8):1668-76. doi: 10.1194/jlr. R600015-JLR200.

12. Jana K, Bera TK, Ghosh D. Antidiabetic effects of Eugenia jambolana in the streptozotocin-induced diabetic male albino rat. Biomark Genom Med. 2015;7(3):116-24. doi: 10.1016/j.bgm.2015.08.001.

13. Matthews DR, Hosker JP, Rudenski AS, Naylor BA, Treacher DF, Turner RC. Homeostasis model assessment: insulin 
resistance and beta-cell function from fasting plasma glucose and insulin concentrations in man. Diabetologia. 1985;28(7):412-9. doi: 10.1007/bf00280883.

14. Pfaffl MW. A new mathematical model for relative quantification in real-time RT-PCR. Nucleic Acids Res. 2001;29(9):e45. doi: 10.1093/nar/29.9.e45.

15. De Magalhães DA, Kume WT, Correia FS, Queiroz TS, Allebrandt Neto EW, dos Santos MP, et al. High-fat diet and streptozotocin in the induction of type 2 diabetes mellitus: a new proposal. An Acad Bras Cienc. 2019;91(1):e20180314. doi: 10.1590/0001-3765201920180314.

16. Manna P, Jain SK. PIP3 but not PIP2 increases GLUT4 surface expression and glucose metabolism mediated by AKT/PKC $/ \lambda$ phosphorylation in 3T3L1 adipocytes. Mol Cell Biochem. 2013;381(1-2):291-9. doi: 10.1007/s11010013-1714-7.

17. Szkudelski T. The mechanism of alloxan and streptozotocin action in B cells of the rat pancreas. Physiol Res. 2001;50(6):537-46.

18. Zierath JR, Houseknecht KL, Gnudi L, Kahn BB. High-fat feeding impairs insulin-stimulated GLUT4 recruitment via an early insulin-signaling defect. Diabetes. 1997;46(2):21523. doi: $10.2337 /$ diab.46.2.215.

19. Yang S, Chen Z, Cao M, Li R, Wang Z, Zhang M. Pioglitazone ameliorates $\mathrm{A} \beta 42$ deposition in rats with dietinduced insulin resistance associated with AKT/GSK3 $\beta$ activation. Mol Med Rep. 2017;15(5):2588-94. doi: 10.3892/ mmr.2017.6342.

20. Nankar RP, Doble M. Ellagic acid potentiates insulin sensitising activity of pioglitazone in L6 myotubes. J Funct Foods. 2015;15:1-10. doi: 10.1016/j.jff.2015.03.010.

21. Wallace TM, Levy JC, Matthews DR. An increase in insulin sensitivity and basal beta-cell function in diabetic subjects treated with pioglitazone in a placebo-controlled randomized study. Diabet Med. 2004;21(6):568-76. doi: 10.1111/j.1464-5491.2004.01218.x.

22. Yin H, Park SY, Wang XJ, Misawa R, Grossman EJ, Tao J, et al. Enhancing pancreatic Beta-cell regeneration in vivo with pioglitazone and alogliptin. PLoS One. 2013;8(6):e65777. doi: 10.1371/journal.pone.0065777.

23. Coskun O, Kanter M, Korkmaz A, Oter S. Quercetin, a flavonoid antioxidant, prevents and protects streptozotocininduced oxidative stress and beta-cell damage in rat pancreas. Pharmacol Res. 2005;51(2):117-23. doi: 10.1016/j. phrs.2004.06.002.

24. Min W, Wu M, Fang P, Yu M, Shi M, Zhang Z, et al. Effect of Baicalein on GLUT4 translocation in adipocytes of dietinduced obese mice. Cell Physiol Biochem. 2018;50(2):42636. doi: 10.1159/000494154.

25. Kahn BB, Pedersen O. Suppression of GLUT4 expression in skeletal muscle of rats that are obese from high fat feeding but not from high carbohydrate feeding or genetic obesity. Endocrinology. 1993;132(1):13-22. doi: 10.1210/ endo.132.1.8419118.

26. Atkinson BJ, Griesel BA, King CD, Josey MA, Olson AL. Moderate GLUT4 overexpression improves insulin sensitivity and fasting triglyceridemia in high-fat dietfed transgenic mice. Diabetes. 2013;62(7):2249-58. doi: $10.2337 / \mathrm{db} 12-1146$.

27. Carvalho E, Kotani K, Peroni OD, Kahn BB. Adiposespecific overexpression of GLUT4 reverses insulin resistance and diabetes in mice lacking GLUT4 selectively in muscle. Am J Physiol Endocrinol Metab. 2005;289(4):E551-61. doi: 10.1152/ajpendo.00116.2005.

28. Skovsø S. Modeling type 2 diabetes in rats using high fat diet and streptozotocin. J Diabetes Investig. 2014;5(4):34958. doi: $10.1111 /$ jdi.12235. 